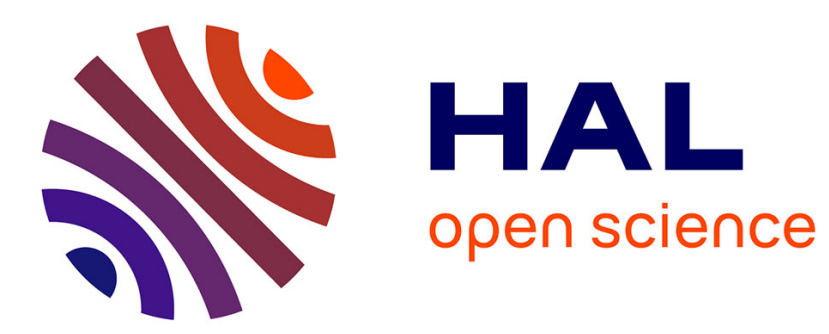

\title{
Mismatches between birds' spatial and temporal dynamics reflect their delayed response to global changes
}

Pierre Gaüzère, Vincent Devictor

\section{To cite this version:}

Pierre Gaüzère, Vincent Devictor. Mismatches between birds' spatial and temporal dynamics reflect their delayed response to global changes. Oikos, 2021, 130, pp.1284 - 1296. 10.1111/oik.08289 . hal-03424083

\section{HAL Id: hal-03424083 https://hal.science/hal-03424083}

Submitted on 18 Nov 2021

HAL is a multi-disciplinary open access archive for the deposit and dissemination of scientific research documents, whether they are published or not. The documents may come from teaching and research institutions in France or abroad, or from public or private research centers.
L'archive ouverte pluridisciplinaire HAL, est destinée au dépôt et à la diffusion de documents scientifiques de niveau recherche, publiés ou non, émanant des établissements d'enseignement et de recherche français ou étrangers, des laboratoires publics ou privés. 


\title{
Mismatches between birds' spatial and temporal dynamics reflect their delayed response to global changes
}

\author{
Authors: Pierre Gaüzère ${ }^{1}$, Vincent Devictor ${ }^{2}$ \\ 'Univ. Grenoble Alpes, Univ. Savoie Mont Blanc, CNRS, LECA, Laboratoire d'Ecologie Alpine, \\ F-38000 Grenoble, France
}

${ }^{2}$ ISEM, Université de Montpellier, CNRS, IRD, EPHE, Montpellier, France

Correspondence: Pierre Gaüzère, email: pierre.gauzere@gmail.com

Running title: Spatial vs temporal patterns in bird populations

Keywords: global change, birds, population, community, dark diversity, time-lagged responses, extinction debt

\begin{abstract}
Global changes alter the dynamics of biodiversity, and are forecasted to continue or worsen in the decades to come. Modelling approaches used to anticipate these impacts are mainly based on the equivalence between spatial and temporal response to environmental forcings, generally called space-for-time substitution. However, several processes are known to generate deviations between spatial and temporal responses, potentially undermining the prediction based on space-for-time substitution. We here used high-resolution data from the french breeding bird survey to quantify and map the deviation between spatial and temporal patterns of bird abundances resulting from the dynamics of 124 species monitored in 2,133 sites between 2001 and 2012. Using independent empirical data, we then tested specific predictions linked to the forcings (anthropogenic activities) and processes (asynchronous biotic responses) potentially generating these deviations. We found that deviations between spatial and temporal patterns of abundances were particularly structured in space for bird communities. Following our predictions, space-time deviations were positively correlated with the human influence on ecosystems, and linked with colonization-extinction ratios and community completeness, two markers of ongoing asynchronous responses to environmental forcings. Our results suggest that the discrepancy between space and time dynamics are related to anthropogenic forcings and disequilibrium responses to these forcings. Investigating deviations between spatial and temporal patterns of biodiversity might open promising perspectives for a formal quantification of disequilibrium state of biodiversity at large spatial scale.
\end{abstract}




\title{
Mismatches between birds' spatial and temporal dynamics reflect their delayed response to global changes
}

Keywords : global change, birds, population, community, dark diversity, time-lagged responses, extinction debt

\begin{abstract}
Global changes alter the dynamics of biodiversity, and are forecasted to continue or worsen in the decades to come. Modelling approaches used to anticipate these impacts are mainly based on the equivalence between spatial and temporal response to environmental forcings, generally called space-for-time substitution. However, several processes are known to generate deviations between spatial and temporal responses, potentially undermining the prediction based on space-for-time substitution. We here used high-resolution data from the french breeding bird survey to quantify and map the deviation between spatial and temporal patterns of bird abundances resulting from the dynamics of 124 species monitored in 2,133 sites between 2001 and 2012. Using independent empirical data, we then tested specific predictions linked to the forcings (anthropogenic activities) and processes (asynchronous biotic responses) potentially generating these deviations. We found that deviations between spatial and temporal patterns of abundances were particularly structured in space for bird communities. Following our predictions, space-time deviations were positively correlated with the human influence on ecosystems, and linked with colonization-extinction ratios and community completeness, two markers of ongoing asynchronous responses to environmental forcings. Our results suggest that the discrepancy between space and time dynamics are related to anthropogenic forcings and disequilibrium responses to these forcings. Investigating deviations between spatial and temporal patterns of biodiversity might open promising perspectives for a formal quantification of disequilibrium state of biodiversity at large spatial scale.
\end{abstract}




\section{Introduction}

Anthropogenic activities bring about strong and rapid environmental changes on Earth, which have considerable impacts on the dynamics of biological diversity at local, regional and global scales (McGill et al. 2015). The negative impact of global changes on biodiversity are projected to continue or worsen in future decades in response to an increase of anthropogenic activities (Díaz et al. 2020). Most modeling approaches used to forecast the fate of biodiversity given future environmental conditions assume that the spatial and temporal patterns of biodiversity responses to the environment are interchangeable (Pickett 1989). For example, this is the hypothesis endorsed when the statistical relationships between the spatial distribution of ecological variable (e.g population abundance, species occurrence, assemblage richness) and a given environmental variable established in space is used to predict how the temporal change in the given environmental variable will affect the ecological variable in time. This so-called space-for-time substitution is an approach commonly used to infer temporal dynamics from spatial patterns (Fukami and Wardle 2005, La Sorte et al. 2009). Space-for-time substitutions have been extensively used to explain and predict the effects of global change on biodiversity and is the cornerstone of Species Distribution Modelling (SDM) applied to future scenarios of climate or land use changes. Although assuming this equivalence is relevant in specific situations (Walker et al. 2010, Blois et al. 2013, Gaüzère et al. 2020a), many studies have emphasized substantial differences between spatial and temporal ecological dynamics (Johnson and Miyanishi 2008). An example is when species respond to a change in their environment by persisting within suboptimal environmental conditions through plasticity or adaptation (Lavergne et al. 2010). Depending on the rate of environmental change and taxa characteristics, biodiversity responses to environmental changes can be synchrone (Adriaens et al. 2006), lagged (Brooks et al. 1999, Ovaskainen and Hanski 2002), or uncorrelated (Gaüzère et al. 2018) with environmental forcing. Moreover, the likely existence of complex temporal dynamics including memory effects and alternate stable states suggests that community response to environmental forcing could depend on the past community state, while the spatial dynamics will not (Blonder et al. 2017). Overall, several processes including non-linear biotic responses to environmental changes and disequilibrium dynamics of biodiversity are expected to create deviations between spatial and temporal patterns.

While many studies have questioned the relevance of space-for-time substitution approaches to describe and forecast biodiversity dynamics (e.g (Blois et al. 2013, Bonthoux et al. 2013), and references above), interpreting the observed deviation between spatial and temporal dynamics has received less attention. Recent theoretical developments in disequilibrium ecology (Blonder et al. 2017) and their empirical application (Gaüzère et al. 2018) suggest that the disequilibrium of a community state in regard to the current environmental conditions can be identified from the mismatch between its temporal dynamic and the expectation from spatial relationship between community and environmental state (Gaüzère et al. 2020a). These approaches, however, are currently limited to a unique environmental dimension (e.g. temperature). Yet, anthropogenic global change is a complex, multi-faceted forcing including changes in land and sea use, direct exploitation of organisms, climate change, pollution, invasion of alien species and their interactive effects (García-Valdés et al. 2015, Gaüzère et al. 2020b). We here propose to confront temporal and spatial patterns of biodiversity without relying on a particular environmental dimension, but rather by considering that spatial and temporal patterns of biodiversity are the outcome of multi-dimensional environmental forcing in both space and time. We assume that a given taxon is more likely to occur in areas where environmental conditions allow for greater population growth rates. This assumption arises from the hypothesis that demographic performance (e.g growth, survival, reproduction and dispersal) are strong determinants of population dynamics, and 
ultimately density (Bohner and Diez 2020). This expectation holds for entire assemblages so that larger populations and higher local species richness can be found in more favourable habitats. For example, there is a common expectation that areas with higher NDVI shelter larger bird populations and species richness (Mcfarland et al. 2012, Nieto et al. 2015).

Under the hypothesis of synchrone biodiversity responses to global changes (assumed by the space-for-time substitution approach), one can expect the temporal response pattern to match expectations from spatial pattern, and thus observe small deviations between spatial and temporal pattern (Box 1). At landscape scale where environmental filtering (Kraft et al. 2015) is the main determinant of population's size and dynamics (i.e. assuming little effect of density dependence, carrying capacity and biotic processes), the abundance of populations (or the richness of communities) situated in more suitable areas are more likely to be larger and exhibit a positive growth rate. This hypothesis is in line with the dynamic equilibrium hypothesis (Jackson and Overpeck 2000). Alternatively, spatial and temporal dynamics being asynchronous, mismatch should emerge from the delayed temporal adjustment of population (or communities) to environmental conditions compared to the observed spatial distribution in abundance (or species richness). A common example lies in the imprint of historical performance on current distributions of long-lived species. Any process that changes performance over time can cause spatial patterns (e.g population size) to deviate from current performance (population trend) (Bohner and Diez 2020). In consequence, deviations measured between temporal and spatial patterns of a given biodiversity attribute should reflect -at least to some extent- the deviation from an equilibrated state between pressure and ecological responses (see Box 1). 
Box 1. How space-time deviation can emerge from asynchronous biodiversity responses to environmental change.

Consider a set of sites in the same region where the environmental suitability determines the population size at a given site (see $a$. in space left panel below). Site $X$ under high environmental suitability exhibits positive relative population size (i.e the population size is larger than average) at time $t_{1}$. Consider also that environmental suitability in area $X$ has rapidly decreased between $t_{1}$ and $t_{2}$. Consequently, at $t_{2} X$ is a site of low suitability that should shelter negative relative population size (i.e the population size is smaller than average), as a result from a rapid decrease in population size (negative trend) between $t_{1}$ and $t_{2}$ (see $b$. in time below, right panel). Under the hypothesis of synchronous response to environmental forcing (black line in b.), the spatial pattern (negative relative population size at $t_{2}$ ) and the temporal pattern (negative trend $t_{1}-t_{2}$ ) match. Under the hypothesis of asynchronous responses (red line in b) to environmental forcing, the relative population size observed at $t_{2}$ will be higher than expected from the environmental suitability, thereby creating a mismatch between the "spatial pattern" (positive relative pop. size) and "temporal pattern" (negative trend). This transitory "excess" of individuals is conceptually similar to the extinction debt (when considering species richness instead of abundance, (Tilman et al. 1994), or alternatively, colonization credit in the case of an increase in environmental suitability (Cristofoli et al. 2010, Jackson and Sax 2010). Overall, the negative population trend coupled with the positive relative pop. size observed at $t_{2}$ indicates that the population size in this area has not yet reached the level that one would expect under environmental conditions. Following this rationale, lagged population responses should imprint the difference between the population sizes and trends. Measuring the "space-time-deviation" is obtained from the difference between the observed temporal trend and the observed relative population size in a given area.
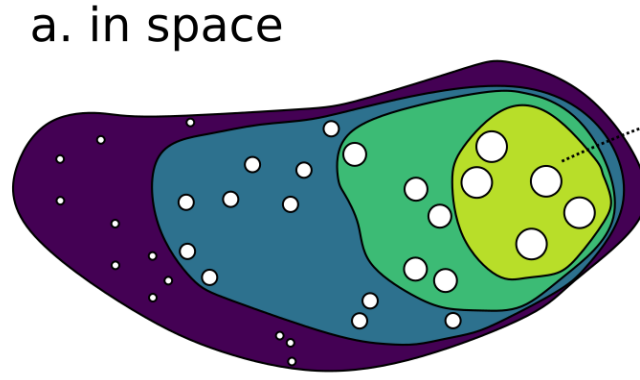

environment suitability

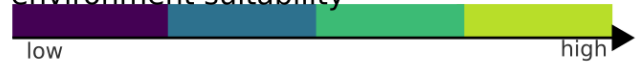

relative population size

\begin{tabular}{lcc}
\multicolumn{1}{c}{0} & 0 \\
$\begin{array}{l}\text { negative } \\
\text { smaller } \\
\text { than average }\end{array}$ & average & $\begin{array}{r}\text { positive } \\
\text { larger } \\
\text { than average }\end{array}$
\end{tabular}

b. in time

example for site $x$

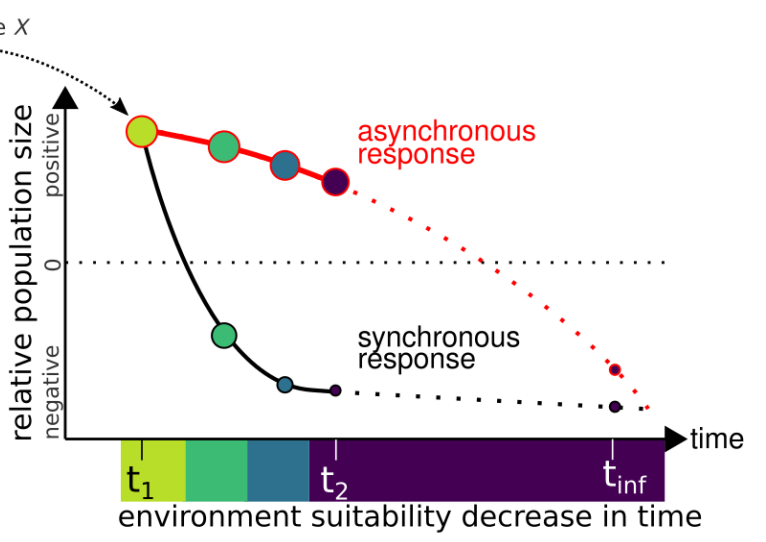

Using quantitative standardized data monitoring the spatial and temporal dynamics of breeding bird populations in France, we estimated and mapped the deviation between spatial and temporal patterns of bird's population size within a set of $209480 \mathrm{~km}$-radius circle areas over more than 10 years. The rationale in using common breeding bird population as an integrative biodiversity feature is that it is commonly used as the basis for many indicators in birds, with well documented decline of common bird population in Europe (Inger et al. 2015) and North America (Rosenberg et al. 2019) over the last 50 years, very likely as a response to recent human-driven global changes. We focused our analyses on landscape-scale, $80 \mathrm{~km}$ radius windows over a 11 years period (2001-2012) in order to compute reliable spatial and temporal patterns for the same area, while avoiding the potentially confounding effect of biotic processes (e.g negative density-dependence), source-sink dynamics, and more generally equilibrium state (Hastings 2004, Blonder et al. 2017, Gaüzère et al. 2018). Within each window, we calculated space-time deviations as the difference between the relative population trend and the relative population size of birds during the study period (Figure 1). A negative space-time deviation indicates a window where bird population size is 
larger than what is "expected" from its temporal trend, and conversely positive space-time deviation indicates populations size smaller than what is expected from its temporal trend. For example, a declining large population will exhibit a negative space-time value, indicating a mismatch between the (large) population size and (negative) growth rate. An increasing small population will exhibit a positive space-time value, indicating a mismatch between the (small) population size and its (positive) growth rate. This approach is in line with recent empirical studies showing mismatches between species distributions and performance (Bohner and Diez 2020) in one hand, and between temporal and spatial patterns (Gaüzère et al. 2020a) on the other hand. Our approach and its related assumptions also stands for species-scale population sizes and community-scale measures such as species richness or biomass. We focused our paper on the analyses of bird's population size because they are the basis of many indicators of large-scale avifauna trends (Rosenberg et al. 2019). However, we repeated our analyses to community-scale bird species richness and total biomass, and for the 124 bird species populations separately. We finally used regression analyses to empirically test a set of predictions related to the forcing and processes potentially driving these space-time deviation. We specifically predicted:

(i) a non-random spatial distribution of space-time deviation. The underlying hypothesis is that space-time deviations are generated by deterministic environmental forcings which are structured in space.

(ii) a negative correlation between deviation values and the impact of anthropogenic activities on ecosystems (Cristofoli et al. 2010, Jackson and Sax 2010). The underlying hypothesis is that - on average - anthropogenic activities are detrimental to bird populations of common breeding birds (Inger et al. 2015, Rosenberg et al. 2019), therefore promote negative space-time deviation ( via asynchronous population responses to recent decrease in environmental suitability.

(iii) a positive correlation between space-time deviation and the extent of natural areas. Conversely, we expect natural areas (i.e less impacted by human activities) to exhibit more positive deviations via asynchronous population responses to recent increase (or stability) in environmental suitability (DeFries et al. 2007, Gaüzère et al. 2016).

(iv) a positive correlation between deviation values and the ratio between local colonization and extinction. Areas exhibiting positive space-time deviation should exhibit more colonization than extinction at local scale, as a result of small increasing populations. Conversely, areas exhibiting negative space-time deviation should have less colonization than extinction at local scale, as a result of large decreasing population (Boulinier et al. 2001, Doherty et al. 2003).

(v) a negative correlation between deviation values and the completeness of communities. The notion of community completeness was developed by (Pärtel et al. 2013), and is based on the ratio between observed local diversity and the number of species that are potentially able to live and reproduce in a given community, but which are currently absent (called dark diversity, (Pärtel et al. 2011). (Pärtel et al. 2013) predicted that contemporary history and the modern influence of human activities should shape local completeness because some communities have had more time to 'collect' individuals (or species) from the surrounding region, while others are marked by local extirpations (Kuussaari et al. 2009, Jackson and Sax 2010).

Validating prediction (i) would indicate that space-time deviation is affected by environmental forcings (along with random processes). Support for predictions (ii) and (iii) while taking into account confounding spatial effects would indicate a direct or indirect effect of anthropogenic 
activities on space-time deviation. Support for prediction (iv) would indicate that space-time deviations are linked to colonization-extinction dynamics at meta-community scale. Support for prediction ( $\mathrm{v}$ ) would indicate that the processes shaping the community completeness and space-time deviation are likely to be similar (i.e. asynchronous responses to increase or decrease in environment suitability). 


\section{Material and Methods}

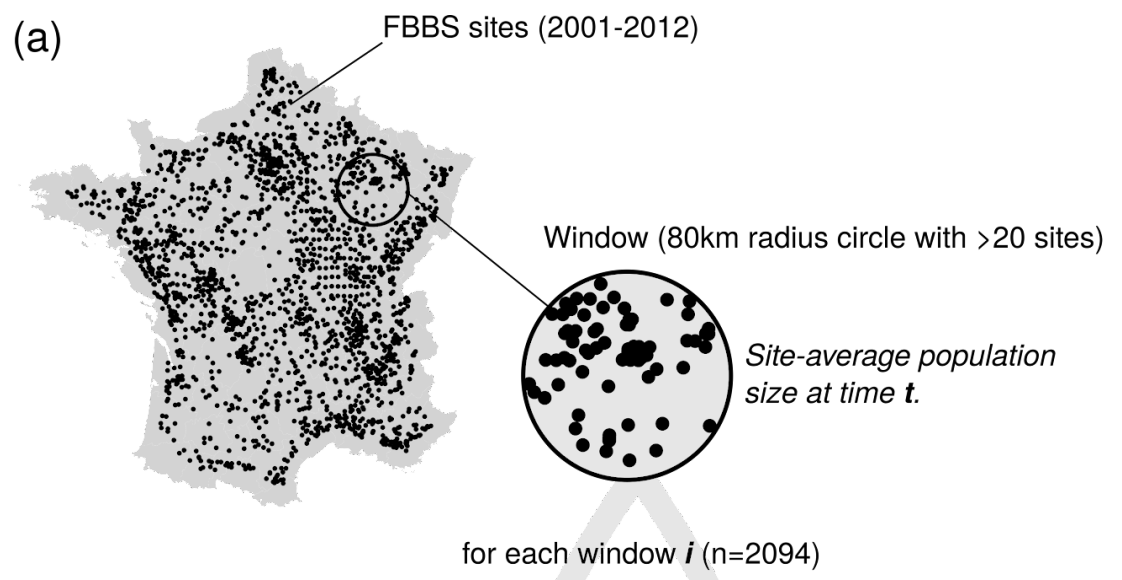

(b)

$$
\begin{aligned}
& \text { Estimate the population trend } \\
& \text { using linear mixed models }
\end{aligned}
$$

\section{Calculate the average} population size over time
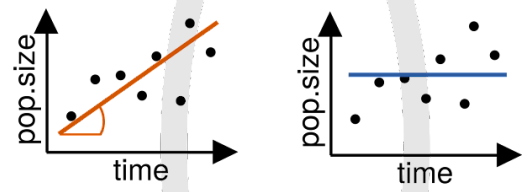

Population trend
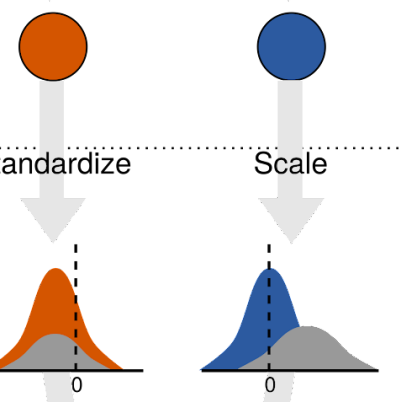

Population size

Relative Relative
population trend

Calculate space-time deviation as the difference between relative population trend and relative population size

(d)
Figure 1. Diagram of the data-processing workflow. Using data from the French Breeding Bird Survey, we (a) applied a moving window approach (see Methods, Moving window) to (b) estimate local population sizes and trends of birds in a spatial continuum of $80 \mathrm{~km}$ radius circle windows covering the whole study area. We then (c) standardized the population trends and scaled the population sizes to compute relative deviation values. For each window, the space-time deviation value (d) was calculated as the difference between the relative population trend and the relative population size. See Methods-Calculating deviation between spatial and temporal dynamics for more details.

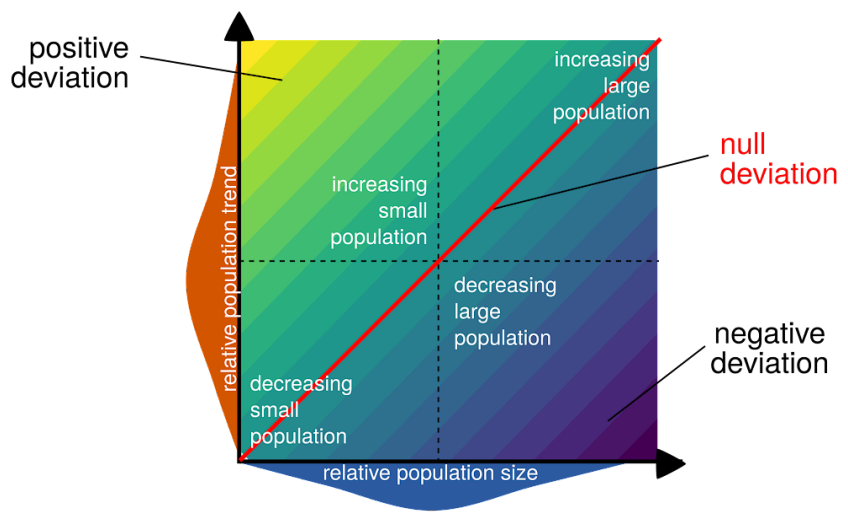




\section{Bird data}

Data were taken from the French Breeding Bird Survey (2001-2012 period, Figure 2a). In this survey, skilled volunteer ornithologists count birds at a given site, following a standardized protocol, at the same site, year after year (Jiguet et al. 2012). Species abundances have been recorded for 2133 sites, each covering $4 \mathrm{~km}^{2}$. Each volunteer provides his/her home locality to the national coordinator, and a $2 \times 2 \mathrm{~km}$ plot to be prospected is randomly selected from within a $10 \mathrm{~km}$ radius (i.e. among 80 possible plots) by the national coordinator. Each spring, volunteers carry out 10 point counts separated by at least $300 \mathrm{~m}$ within the selected $2 \times 2 \mathrm{~km}$ site, for a fixed period of five minutes. Two sampling sessions are realized from 1st April to 8th May, then from 9th May to end of June (in order to detect both early and late breeders), with 4-6 weeks between both sessions. Counts must be repeated on approximately the same date each year ( \pm 7 days), and at dawn (1-4 hours after sunrise) by the same observer, in the same order. The maximum per-point count from these two sessions is retained as the measure of point-level species abundance. The French breeding bird survey have been designed to monitor population trends of the common bird species in France. Therefore, uncommon species are inadequately monitored by this scheme, and might inflate inter-annual variability at site scale and more generally lead to spurious estimations of population trends. We therefore excluded very rare birds and incorrectly monitored species (e.g. specific waterbirds in rare habitats) from our dataset by limiting the final data sample to the 124 bird species representing $99 \%$ of total abundance.

\section{Moving window}

While the FBBS provides a large number of observations and a high density of sites across France, all sites do not have equal temporal coverage (average temporal coverage of FBBS sites : 4.73 years \pm 3.20 [mean $\pm \mathrm{sd}$ ]). In order to provide reliable estimates of local population sizes and trends of birds in a spatial continuum covering the whole study area and period (among other reasons stated in the introduction), we used a spatial moving window approach (Figure 1a). The principle is to calculate relevant metrics within a moving window delineated by a circle around a given focal site. This is a straightforward way to summarize both local spatial and temporal trends emerging from regional dynamics (Gaucherel 2007, Gaucherel et al. 2008) and has been already valuably used with this dataset (Devictor et al. 2010, Godet et al. 2015, Gaüzère et al. 2017). Each window is a $80 \mathrm{~km}$-radius circle centered on a focal site, and encompassing at least 20 sites. This resulted in 2094 windows of similar size. Note that the radius of $80 \mathrm{~km}$ was a compromise between spatial resolution, minimum number of sites within the window, and the resulting number of windows to cover the study area (for more details, see (Gaüzère et al. 2015). Because the same site can be integrated in more than one window, the estimates produced by this approach are correlated in space. We therefore explicitly integrated this spatial structure in subsequent analysis (see Statistical analysis section).

\section{Calculating deviation between spatial and temporal dynamics}

For each window, space-time deviation was calculated as the difference between the relative population trend and the relative population size of birds during the period 2001-2012 (Figure 1d). The relative population trend was estimated as the scaled change in bird abundance (all species together) per unit of time (year), see Figure 1b. First, we used linear mixed models performed with the Imer\{Ime4\} function in R (R Development Core Team 2013, Douglas Bates et al. 2015) to estimate temporal population trend. In these models (one for each window), the response variable was the log-transformed total abundance of birds (calculated for a given site at a given year), regressed over a fixed effect of year (2001-2012). The uncontrolled variability between sites 
(observers, habitat) and species (life-history traits such as mass) was taken into account by adding a random effect of species nested in the site in our model. The fixed-effect year coefficient (i.e the slope) indicated the temporal population trend over the 12 years of the survey. Temporal trends values were then scaled by dividing each value by the standard deviation of the vector $(n=2094)$ in order to compute relative population trends. We do not centered (subtracting the mean of the vector) population trend values in order to keep the natural sign of population trend in subsequent analyses (Figure 1c).

The relative site-scale population size was calculated as the scaled-centered average bird abundance over the study period (Figure 1b). We first calculated the average population size of each site over the period of survey. Average population sizes were then centered by subtracting each value by the mean of the vector, and scaled by dividing each value by the standard deviation of the vector in order to compute the relative population size (Figure 1c). Negative values of relative population size indicates a window where bird population is smaller than the average breeding bird population size in France, and conversely for positive values indicates populations larger than average. Note that we here investigated spatial and temporal patterns of abundance, but this method can be applied to other variables of interest. For example, we calculated space-time deviation based on community species richness, and total bird biomass (see supplementary figure S4). Any type of biodiversity measures can be considered (e.g. diversity, similarity, or functional composition). We also repeated our analyses based on individual species-specific data in order to assess space-time deviation for each 124 species separately.

\section{Predictors of space-time deviation}

Human influence index. We used the Global Human Influence Index (HII) (version 2, Wildlife Conservation Society and Center for International Earth Science Information Network, Columbia University, 2005) from the NASA Socioeconomic Data and Applications Center as a proxy of a multi-dimensional anthropogenic pressure on ecosystems. This index estimates the direct human footprint on ecosystems (Sanderson et al. 2002) as a proxy of recent human pressure on biodiversity. It incorporates nine global data layers corresponding to: human population pressure (population density); human land use and infrastructure (built-up areas, nighttime lights, land use, and land cover); and human access (coastlines, roads, railroads, navigable rivers). HII values at $1 \mathrm{~km}$ resolution were extracted for each of the monitored sites, and averaged for each window.

Natural area extent. We used the percent of natural area as a proxy measuring the extent of natural surface in the window. The percent of natural area in the window was based on landscape composition data from CORINE Land Cover 2006 raster data (European Environment Agency 2010) for each $80 \mathrm{~km}$-radius window. In order to be able to consider large-scale biogeographical gradients, CORINE Land Cover classes were aggregated as a function of their top-level nomenclature, namely: artificial surfaces, agricultural areas, forest and semi-natural areas, wetlands, and water bodies (European Environment Agency 2007). We then computed the percentage land cover (calculated as the habitat class area, in square meters, over total land area of the window) for the first three of these classes, in order to define landscape composition variables : \% artificial area, \% agricultural area, and \% natural area. In the CORINE nomenclature, natural areas encompasses broad-leaved forest, coniferous forest, mixed forest, natural grasslands, moors and heathland, sclerophyllous vegetation, transitional woodland-shrub, beaches, dunes, sands, bare rocks, sparsely vegetated areas, burnt areas, glaciers and perpetual snow.

Colonization-extension ratio. We calculated colonization-extinction ratio by first selecting all sites monitored for at least three consecutive years (representing $58 \%$ of the total dataset). For each site, we used the betadiver function in the $\mathrm{R}$ vegan package ( $\mathrm{R}$ Development Core Team 2013, 
Oksanen et al. 2015) to compute, for each pair of consecutive years: the number of species present in both years (a); the number of colonizing species, i.e species recorded in year $\mathrm{t}+1$ that were not present in year $t(b)$; the number of extinct species (c); and the total number of species $S$ $(a+b+c)$. For each site, the colonization-extinction ratio was calculated as the average of $b / c$ for pairs of consecutive years. These site-scale colonization-extinction ratio values were then averaged for each window. A value $>1$ indicates that the site in the focal window experience more colonization than extinction, anc conversely for values $<1$.

Completeness of community. The completeness of each community Index was calculated as the log-ratio of dark and observed diversity (Pärtel et al. 2013): In(observed richness/dark diversity). Dark diversity represents the number of species that would be environmentally and ecologically suited to conditions in the target local species pool, but which are absent from the observed community. It was estimated at point-count scale over all the study period using the co-occurrence method presented in (Lewis et al. 2016). An absent species is considered to be part of the local species pool if it typically co-occurs with the species that are observed in the focal community. We selected this method because it is more accurate than the method based on measurements of similarity in ecological requirements (Lewis et al. 2016) and because we lack information on point-scale environmental conditions. The probability of species co-occurrence was estimated by Beals index (Beals 1984, De Cáceres and Legendre 2008) calculated from the point-scale community matrices (2001-2012) using the beals \{vegan\} R function. Each species absent from the observed species pool was considered to be in the local pool (i.e dark diversity) if the probability of co-occurrence was $>0.95$ ( $5 \%$ threshold). This threshold is arbitrary, and the presence of outliers, which are common in co-occurrence probability distributions can affect the outcome (Botta-Dukát 2012). We therefore modeled the first, fifth and tenth percentile thresholds in order to ensure the robustness of our estimations (Figure S1). Site-scale completeness values were then averaged for each window.

\section{Statistical analyses}

We tested prediction (i) by implementing a generalized additive mixed model (GAMM) testing for a non-random spatial distribution of space-time deviation, where space-time deviation was regressed over a two-dimensional spline smoothing based on geographic coordinates with a free degree of freedom. We introduced the factorial variable biogeographic domain (Mediterranean, Continental, Alpine, Atlantic) as a random effect to account for regional variability in climate and species pools. We also tested linear variation of space-time deviation along latitude and longitude by implementing two linear mixed models (LMM) where space-time deviation was regressed over latitude or longitude, with random effect of biogeographic domain.

We tested prediction (ii - v) by implementing generalized additive mixed models (GAMM) testing the statistical relationships between space-time deviation and predictors linked to the predictions (ii: human influence index, iii: Natural area extent, iv: Colonization-extension ratio, v: completeness of community). We ran four models (one for each prediction) in which space-time deviation (calculated for each window, $n=2094$ ) was the response variable regressed over each explanatory variables (predictors) previously scaled. We considered that each prediction as an independent test as the predictors were uncorrelated (see Figure S2). We estimated the linear effect of each explanatory variable and added a two-dimensional spline-based smoothing with a free degree of freedom based on geographic coordinates to explicitly account for the non-random spatial structure of deviation (Wood 2006) and prevent issue linked to spatial autocorrelation in model residuals. The biogeographic domain (factorial variable : Mediterranean, Continental, Alpine, Atlantic) was introduced as a random effect to account for regional variability in climate and 
species pools. For the model testing the relationship between space-time deviation and community completeness (prediction iv) we added the average site species richness as a fixed-effect co-variable in the model to account for its potential confounding effect (local richness is correlated to community completeness). Models residuals were formally checked for normality, homoscedasticity, and absence of correlation with predicted values and spatial autocorrelation, and passed in all cases.

Code and data availability. All the code used for data analysis, and data on raw population abundance and trend per moving window can be accessed at https://github.com/pgauzere/Disequilibrium Values 


\section{Results}

\section{Patterns of space-time deviation}

The relative temporal trend was positively correlated with the relative population size of birds populations (linear model, $0.14 \pm 0.021, t=10.511, \mathrm{df}=2$, $\mathrm{p}$-value $<0.0001$, Figure 2a black line), but the relationship explained a small amount of variance (linear model adjusted $R^{2}=0.019$ ). The distribution of space-time deviation values calculated as the difference between relative temporal trend and relative population size showed a bimodal distribution dispersed around the line 1:1 median (red line in Figure $2 a$ and $2 b$ ). Values ranged from -2.8 to 4.27 , with a mean $\pm S D=0.234 \pm$ 1.280 (Figure 2b).
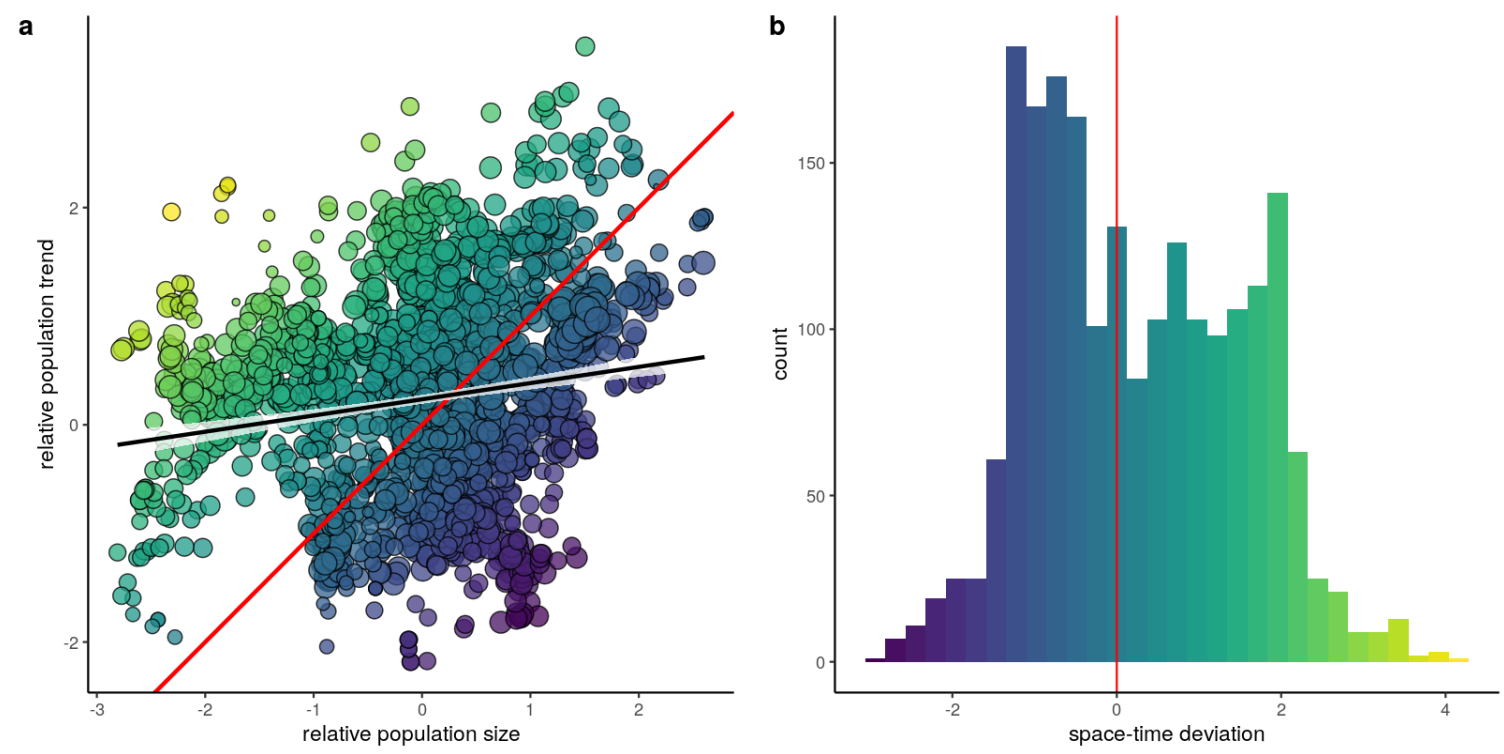

Figure 2. a : scatterplot of relative bird population temporal trends ( $y$-axis) vs relative population size (x-axis). Each point corresponds to a window, with the color showing the space-time deviation (see $b$ for scale) calculated as the difference between relative population trend ( $y$-axis) and relative population size ( $x$-axis). The shaded, black line represents the linear relationship (slope \pm SE) between relative temporal trends and relative size. Point size correspond to the inversed value of standard error associated with the estimation of the temporal trend used as a weight in subsequent statistical analyses. b : histogram of the distribution of space-time value. Red lines in a and b represent equality between relative population trend and relative population size, i.e space-time deviation $=0$. 
Space-time deviation was not randomly distributed in space (GAMM geographic coordinates two-dimensional spline-smoothing term, $t=28.8$, total edf=180.1, $p$-value $<0.001$ ). Mapping the deviation over France revealed a clear spatial structure with more positive deviation in the Mediterranean biogeographical domain (South-East France, Figure 3a) and negative deviation in the Atlantic biogeographic domain (West side of the country, Figure 3a). Space-time deviation decreased with Latitude (Figure $3 b$, LMM linear fixed effect coefficient $=-0.10 \pm 0.028, t=-3.55$, $\mathrm{df}=2018$, $\mathrm{p}$-value $<0.001$ ) and increased with Longitude (Figure 3c, LMM linear fixed effect coefficient $=0.43 \pm 0.027, t=15.77, d f=2018, p$-value $<0.001)$.

Calculating space-time deviation for each species separately revealed a strong inter-specific variability. For example, the European crested tit Parus cristatus mainly exhibited positive deviation values (Figure S3a), while others species such as the Eurasian collared dove Streptopelia decaocto or the Common blackbird Turdus Merula mainly showed negative deviations (Figure S3b and S3c). Space-time deviation based on bird's species population size was correlated with deviation based on community richness (Pearson's correlation coefficient: 0.743 , Figure S4a) and total bird biomass (Pearson's correlation coefficient: 0.879, Figure S4b).
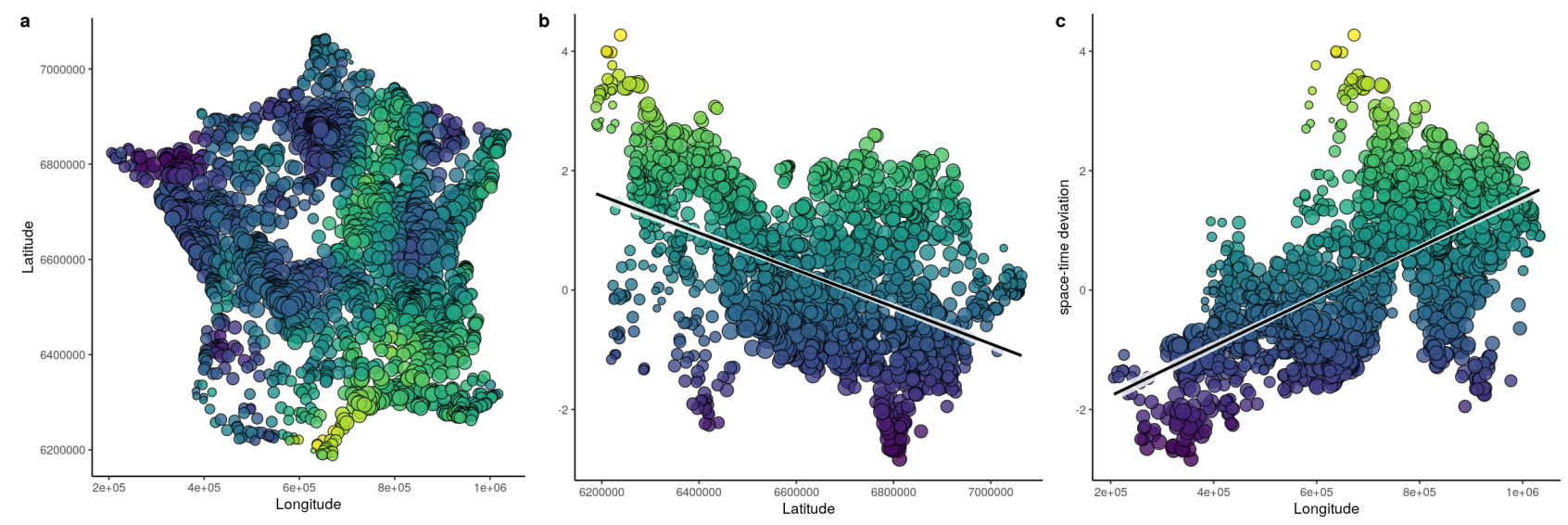

Figure 3. a : map of France (Lambert II coordinates) showing the spatial distribution of space-time deviation. Each point represents the center of an $80 \mathrm{~km}$-radius circular window. Color shows the deviation value, as reported in $y$-axis in b and c. b and c: scatterplots showing the variation of space-time deviation with Latitude and Longitude, respectively. 


\section{Correlations between space-time deviation and predictors}
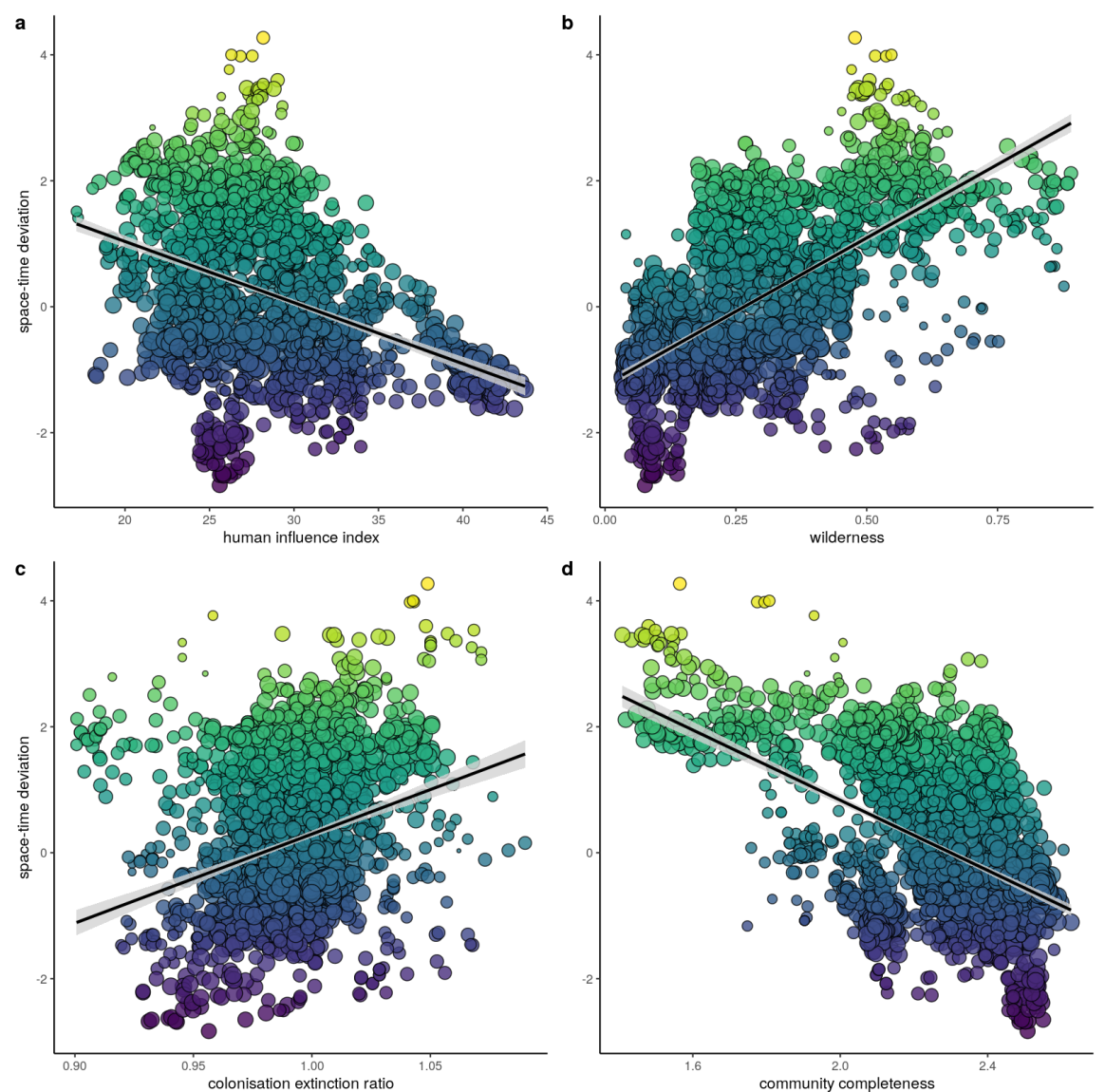

Figure 4. Partial residual plots of models testing the linear relationship between space-time deviation and (a) the colonization-extinction ratio, (b) the completeness of communities, (c) the human influence index, and (d) natural area extent (i.e the percent of natural area in the window). Point size corresponds to the inverse standard error (1\SE) associated with estimates of temporal temporal trend incorporated as a weight in the models. Spatial autocorrelation pattern was explicitly incorporated in models by a two-dimensional spline with a free degree of freedom based on geographic coordinates. The biogeographic domain was introduced as a random effect in models to account for regional variability in climate and species pools.

Space-time deviation was negatively correlated with human influence index (Figure 4a, GAMM linear fixed effect coefficient $=-0.23 \pm 0.036, t=-6.098$, total edf $=30.78$, Wald test $p$-value $<0.0001$, linear model adjusted $\mathrm{R}^{2}=0.176$ ), and positively correlated with the extent of natural area (Figure $4 b$, GAMM linear fixed effect coefficient $=0.70 \pm 0.024, t=29.05$, total edf $=28.86$, Wald test $p$-value < 0.001). The estimated linear fixed-effect of natural area explained about $30 \%$ of the variance in space-time deviation (linear model adjusted $\mathrm{R}^{2}=0.29$ ).

Space-time deviation was positively correlated with the ratio between local colonization and extinction ratio (Figure 4c, GAMM linear fixed effect coefficient $=0.21 \pm 0.020$ [mean \pm Standard Error], $t=10.8$, total edf $=29.89$, Wald test $p$-value $<0.0001$ ), although the estimated fixed-effect of colonization-extinction ratio had a low explanatory power (linear model adjusted $\mathrm{R}^{2}=0.076$ ).

Space-time deviation was negatively correlated with community completeness, i.e more complete communities tend to exhibit negative deviation values. (Figure 4d, GAMM linear fixed effect coefficient $=-0.25 \pm 0.036$ [mean \pm Standard Error], $t=-7.097$, total edf $=30.88$, Wald test $p$-value $<$ 0.001 , linear model adjusted $R^{2}=0.26$ ). 


\section{Discussion}

The observed deviation between temporal and spatial patterns of bird population dynamics was not randomly distributed in space, and correlated to gradients of potential anthropogenic pressure and environmental variables. Based on a correlative approach, our results confirmed our predictions linked to candidate forcings and processes likely to generate these deviations. They further suggest that our quantification of space-time deviation might reflect asynchronous bird responses to modern anthropogenic global changes.

The dynamics of bird populations at the local level are determined by multi-scale environmental gradients that include climate (Stephens et al. 2016), habitat composition, and human activities (Kilgore 1971, Dolman and Sutherland 1995). Because these constraints have spatial and temporal effects on populations, an "equilibrium dynamic" response to variations in multi-scale environmental gradients would imply a synchrone, linear and proportional response of biodiversity in space and time. Synchronous biodiversity response should further support the space-for-time substitution whereby the temporal trend is correlated to the distribution of relative abundances. Although our results suggest that such a relation exists, it is very blurred : bird's relative population size explained less than $2 \%$ of the variance in population trends. Beyond this weak support for equivalence between spatial and temporal patterns, we here investigated the information potentially hidden in the discrepancy between variation of abundance in space and time. We showed that space-time deviations were clearly structured in space, with areas supporting space-time equivalence and other exhibiting strong positive or negative deviation. This result supports prediction (i), suggesting that our measure of deviation is not solely resulting from stochastic processes or sampling error, but is also driven by spatially structured forcings. While it is very likely that stochasticity and sampling error largely contribute to creating discrepancies between temporal and spatial patterns, deviation may also be generated by deterministic processes. One of the main hypotheses lies in the existence of asynchronous, mismatched biodiversity responses to environmental change (Ernoult et al. 2006, Metzger et al. 2009). A mismatched response implies all the processes preventing a synchronous, linear and proportional response of a given biodiversity feature to a one- or multi- dimensional environmental space. , and its distal causes are related to non-linear environmental responses, biotic interactions, demography, or complex temporal dynamics resulting from memory effects.

To explore the imprint of the forcings and underlying processes in temporal bird dynamics, we further tested the correlation between the distribution of space-time deviation and large-scale markers of human influence on ecosystems derived from independent datasets. The negative correlation observed between the human influence index and space-time deviation supported prediction (ii). Under low human influence (i.e index value $<30$ ) space-time deviation was either positive or negative (Figure 4a). However, under strong human influence (index value $>30$ ), space-time deviation was always negative (Figure 4a) and driven by negative population trends (supplementary Figure S5). This result suggests a negative human influence on bird populations over the last decades, generating asynchronous negative response (lagged decrease in population size, (Kuussaari et al. 2009) to recent anthropogenic global change responsible for the observed deviation between spatial and temporal patterns. We also showed that more natural areas were linked to more positive deviation, thereby supporting prediction (iii) (note that the percentage of natural areas and the human influence index were not correlated, Figure S2). Negative deviation in regions including low proportion of natural areas was mainly driven by large and decreasing populations (i.e positive relative abundance and negative relative population trend), while positive deviation in high natural areas was linked with small-stable bird populations (see Figure S5). This 
suggests that bird populations in forest and semi-natural areas are temporarily stable, but that large bird populations in areas of low naturalness (mainly agricultural habitats) have asynchronous responses to decrease in environmental suitability over the last decades. Together, our results are consistent with the observation that strong human imprints on ecosystems are linked to a lower ability of bird populations to cope with rapid global changes (Loh et al. 2005, Díaz et al. 2020). They also suggest that many bird populations under strong human influence are doomed to decrease in the near future, if no actions are promptly taken to increase the overall environmental suitability in the area. On the other hand, these results suggest that natural landscapes with little human imprint, or protected areas (see supplementary S2), benefit to biodiversity under global changes (Cristofoli et al. 2010, Gaüzère et al. 2016) and might drive an ongoing recovery of particular populations (Inger et al. 2015).

We further hypothesized that markers of transient community dynamics should be related to the spatial distribution of space-time deviation resulting from asynchronous population responses to environmental forcings. We first predicted more extinctions that colonizations (i.e colonization extinction ratio $<1$ ) in areas with negative deviation, because populations responding to a shift towards less favorable environmental conditions should exhibit more local extinction -with the reverse being true for positive deviations (Hastings 2004, Jackson and Sax 2010). Our results confirmed prediction (iv), although the relation between deviation and colonization-extinction ratio had little (but statistically clear) explicative power. We also predicted community completeness to be related to space-time deviations because they are likely to be shaped by the same non-equilibrium processes. Although variation in species richness can, in specific situations, be attributed to natural processes and anthropogenic impacts, the observed number of species offers little insight into how complete communities are compared to the potential of local habitat (Pärtel et al. 2011, 2013, Zobel et al. 2011). We predicted that when a forcing leads to positive deviation, the community completeness should be lower because the observed species pool therefore represents a lower proportion of the habitat-specific species pool. The strong negative correlation between debt-credit values and completeness revealed by our analysis clearly supports prediction (v), and concur with earlier work on dark diversity (Pärtel et al. 2011, 2013). However, these results contrast with (Ronk et al. 2015) showing lower completeness for plant communities in the most anthropized areas resulting from intensive land use leading to local extinctions (Ellis et al. 2012). Our data showed a weak relationship between completeness and human impact (linear $\mathrm{R}^{2}=0.035$, Figure S2), inconsistent with the negative relationship between space-time deviation and human influence. While Ronk et al. (2015) interpreted this result as the effect of recent anthropogenic extinctions that shaped community completeness at a very local scale, our study probably captured the effect of delayed biodiversity responses to past global changes, a process that operates principally at the meta-community scale.

Although asynchronous responses of biodiversity to environmental shifts are well-known and documented in theoretical (Norberg et al. 2012) and empirical work (Krauss et al. 2010), conservation biologists have been slow to recognize them as a potential source of misconceptions in observed patterns of biodiversity. In certain context, the measured impact of global change may be greater (or smaller) than observed one due to the delayed response of biodiversity to climate (Devictor et al. 2008, Bertrand et al. 2011, 2016, Gaüzère et al. 2017, 2018, Alexander et al. 2018) and land use changes (Kuussaari et al. 2009, Krauss et al. 2010, Norberg et al. 2012).

Because non-equilibrium dynamics are often overlooked in ecological studies, biodiversity monitoring might be more a snapshot of ongoing dynamics than an exact estimate of the state and fate of biodiversity. Identifying the impact of asynchronous response in empirical biodiversity 
patterns is important to assess the accuracy of punctual biological surveys of the current and local state of biodiversity, and whether they are still imprinted by past environmental changes (Sandel et al. 2011, Sandel 2019). For now, successful approaches have either focused on particular environmental forces such as climate change, habitat loss (Halley et al. 2016), and landscape change (Adriaens et al. 2006), or have confronted current biodiversity states with past and present conditions (Halley et al. 2016, Ordonez and Svenning 2016). For example, local extinction debt and lagged responses can be inferred from a better (or additional) explanatory power of past than current environmental patterns (Dupouey et al. 2002, Blonder et al. 2018). The application of this approach is, however, impaired by the lack of information available to describe past land use, habitat structure and composition at large spatial scale. We here proposed a simple and straightforward approach to estimate deviation between spatial and temporal patterns, under the assumption that both dynamics of biodiversity are sensitive to environmental variations in space and time. Our analyses brought evidence suggesting that our measure of space-time deviation is imprinted by asynchronous responses to recent global change. Although the relative nature of our deviation measure prevents a formal, exact quantification of the disequilibrium state of biodiversity, space-time deviations are likely to provide a rough assessment of areas under the influence of positive (colonization credits) or negative (extinction debt) disequilibrium states. We argue that the comparison of spatial and temporal dynamics is a promising step in this new research avenue, with respect to the quantitative estimation of the imprint of past and current environmental changes on observed local diversity. In a world that is facing intense and rapid global change, the investigation of the seldom studied transient dynamics will shed new light on biodiversity patterns and processes. 


\section{References}

Adriaens, D. et al. 2006. No evidence of a plant extinction debt in highly fragmented calcareous grasslands in Belgium. - Biol. Conserv. 133: 212-224.

Alexander, J. M. et al. 2018. Lags in the response of mountain plant communities to climate change. - Glob. Chang. Biol. 24: 563-579.

Beals, E. W. 1984. Bray-Curtis Ordination: an effective strategy for analysis of multivariate ecological data. - Adv. Ecol. Res. 14: 1-55.

Bertrand, R. et al. 2011. Changes in plant community composition lag behind climate warming in lowland forests. - Nature 479: 9-12.

Bertrand, R. et al. 2016. Ecological constraints increase the climatic debt in forests. - Nat. Commun. 7: 12643.

Blois, J. L. J. L. et al. 2013. Space can substitute for time in predicting climate-change effects on biodiversity. - Proceedings of the National Academy of Sciences 110: 9374-9379.

Blonder, B. et al. 2017. Predictability in community dynamics. - Ecol. Lett. 20: 293-306.

Blonder, B. et al. 2018. Late Quaternary climate legacies in contemporary plant functional composition. - Glob. Chang. Biol. 24: 4827-4840.

Bohner, T. and Diez, J. 2020. Extensive mismatches between species distributions and performance and their relationship to functional traits. - Ecol. Lett. 23: 33-44.

Bonthoux, S. et al. 2013. Contrasting spatial and temporal responses of bird communities to landscape changes. - Oecologia 172: 532-574.

Botta-Dukát, Z. 2012. Co-occurrence-based measure of species' habitat specialization: Robust, unbiased estimation in saturated communities. - J. Veg. Sci. 23: 201-207.

Boulinier, T. et al. 2001. Forest fragmentation and bird community dynamics: inference at regional scales. - Ecology 82: 1159-1169.

Brooks, T. M. et al. 1999. Time Lag between Deforestation and Bird Extinction in Tropical Forest Fragments. - Conserv. Biol. 13: 1140-1150.

Cristofoli, S. et al. 2010. Colonization Credit in Restored Wet Heathlands. - Restor. Ecol. 18: 645-655.

De Cáceres, M. and Legendre, P. 2008. Beals smoothing revisited. - Oecologia 156: 657-669.

DeFries, R. et al. 2007. Land use change around protected areas: management to balance human needs and ecological function. - Ecol. Appl. 17: 1031-1038.

Devictor, V. et al. 2008. Birds are tracking climate warming, but not fast enough. - Proceedings of the Royal Society 275: 2743-2748.

Devictor, V. et al. 2010. Spatial mismatch and congruence between taxonomic, phylogenetic and functional diversity: the need for integrative conservation strategies in a changing world. Ecol. Lett. 13: 1030-1040.

Díaz, S. et al. 2020. Summary for policymakers of the global assessment report on biodiversity and ecosystem services of the Intergovernmental Science-Policy Platform on Biodiversity and Ecosystem Services.

Doherty, P. F. et al. 2003. Sexual selection affects local extinction and turnover in bird communities. - Proceedings of the National Academy of Sciences 100: 5858-5862.

Dolman, P. M. and Sutherland, W. J. 1995. The response of bird populations to habitat loss. - Ibis 137: S38-S46.

Douglas Bates, M. M. et al. 2015. Fitting linear mixed-effects models using Ime4. - J. Stat. Softw. 67: $1-48$.

Dupouey, J. L. et al. 2002. Irreversible Impact of past Land Use on Forest Soils and Biodiversity. Ecology 83: 2978.

Ellis, E. C. et al. 2012. All is not loss: plant biodiversity in the anthropocene. - PLoS One 7: e30535. 
Ernoult, A. et al. 2006. Potential landscape drivers of biodiversity components in a flood plain: Past or present patterns? - Biol. Conserv. 127: 1-17.

European Environment Agency 2007. CLC2006 technical guidelines. 2010: 70.

European Environment Agency 2010. Corine Land Cover 2006 raster data. http://www.eea.europa.eu/data-and-maps/data/corine-land-cover-2006-raster

Fukami, T. and Wardle, D. A. 2005. Long-term ecological dynamics: reciprocal insights from natural and anthropogenic gradients. - Proc. Biol. Sci. 272: 2105-2115.

García-Valdés, R. et al. 2015. Evaluating the combined effects of climate and land-use change on tree species distributions. - J. Appl. Ecol. 52: 902-912.

Gaucherel, C. 2007. Multiscale heterogeneity map and associated scaling profile for landscape analysis. - Landsc. Urban Plan. 82: 95-102.

Gaucherel, C. et al. 2008. The comparison map profile method: A strategy for multiscale comparison of quantitative and qualitative images. - IEEE Trans. Geosci. Remote Sens. 46: 2708-2719.

Gaüzère, P. et al. 2015. Rapid adjustment of bird community compositions to local climatic variations and its functional consequences. - Glob. Chang. Biol. 21: 3367-3378.

Gaüzère, P. et al. 2016. Can protected areas mitigate the impacts of climate change on bird's species and communities? (R Loyola, Ed.). - Diversity and Distributions 22: 625-637.

Gaüzère, P. et al. 2017. Where do they go? The effects of topography and habitat diversity on reducing climatic debt in birds. - Glob. Chang. Biol. 23: 2218-2229.

Gaüzère, P. et al. 2018. Empirical Predictability of Community Responses to Climate Change. Frontiers in Ecology and Evolution 6: 186.

Gaüzère, P. et al. 2020a. Equilibrium in plant functional trait responses to warming is stronger under higher climate variability during the Holocene (A Tomasovych, Ed.). - Glob. Ecol. Biogeogr. 44: 317.

Gaüzère, P. et al. 2020b. Long-term effects of combined land-use and climate changes on local bird communities in mosaic agricultural landscapes. - Agriculture, Ecosystems \& Environment 289: 106722.

Godet, L. et al. 2015. Dissociating several forms of commonness in birds sheds new light on biotic homogenization. - Glob. Ecol. Biogeogr. 24: 416-426.

Halley, J. M. et al. 2016. Dynamics of extinction debt across five taxonomic groups. - Nat. Commun. 7: 1-6.

Hastings, A. 2004. Transients: The key to long-term ecological understanding? - Trends Ecol. Evol. 19: 39-45.

Inger, R. et al. 2015. Common European birds are declining rapidly while less abundant species' numbers are rising (J Hill, Ed.). - Ecol. Lett. 18: 28-36.

Jackson, S. T. and Overpeck, J. T. 2000. Responses of Plant Populations and Communities to Environmental Changes of the Late Quaternary. - Paleontological Society 26: 194-220.

Jackson, S. T. and Sax, D. F. 2010. Balancing biodiversity in a changing environment: extinction debt, immigration credit and species turnover. - Trends Ecol. Evol. 25: 153-160.

Jiguet, F. et al. 2012. French citizens monitoring ordinary birds provide tools for conservation and ecological sciences. - Acta Oecol. 44: 58-66.

Johnson, E. A. and Miyanishi, K. 2008. Testing the assumptions of chronosequences in succession. - Ecol. Lett. 11: 419-431.

Kilgore, B. M. 1971. Response of Breeding Bird Populations to Habitat Changes in a Giant Sequoia Forest. - Am. Midl. Nat. 85: 135-152.

Kraft, N. J. B. et al. 2015. Community assembly, coexistence and the environmental filtering metaphor. - Functional in press.

Krauss, J. et al. 2010. Habitat fragmentation causes immediate and time-delayed biodiversity loss 
at different trophic levels. - Ecol. Lett. 13: 597-605.

Kuussaari, M. et al. 2009. Extinction debt: a challenge for biodiversity conservation. - Trends Ecol. Evol. 24: 564-571.

La Sorte, F. A. et al. 2009. Disparities between observed and predicted impacts of climate change on winter bird assemblages. - Proc. Biol. Sci. 276: 3167-3174.

Lavergne, S. et al. 2010. Biodiversity and Climate Change: Integrating Evolutionary and Ecological Responses of Species and Communities. - Annu. Rev. Ecol. Evol. Syst. 41: 321-350.

Lewis, R. J. et al. 2016. Estimating dark diversity and species pools: an empirical assessment of two methods (N Isaac, Ed.). - Methods Ecol. Evol. 7: 104-113.

Loh, J. et al. 2005. The Living Planet Index: using species population time series to track trends in biodiversity. - Philos. Trans. R. Soc. Lond. B Biol. Sci. 360: 289-295.

Mcfarland, T. M. et al. 2012. Evaluation of NDVI to assess avian abundance and richness along the upper San Pedro River. - J. Arid Environ. 77: 45-53.

McGill, B. J. et al. 2015. Fifteen forms of biodiversity trend in the Anthropocene. - Trends Ecol. Evol. 30: 104-113.

Metzger, J. P. et al. 2009. Time-lag in biological responses to landscape changes in a highly dynamic Atlantic forest region. - Biol. Conserv. 142: 1166-1177.

Nieto, S. et al. 2015. Can temporal and spatial NDVI predict regional bird-species richness? - Global Ecology and Conservation 3: 729-735.

Norberg, J. et al. 2012. Eco-evolutionary responses of biodiversity to climate change. - Nat. Clim. Chang. 2: 747-751.

Oksanen, J. et al. 2015. vegan: Community Ecology Package.

Ordonez, A. and Svenning, J.-C. 2016. Strong paleoclimatic legacies in current plant functional diversity patterns across Europe. - Ecol. Evol. 6: 3405-3416.

Ovaskainen, O. and Hanski, I. 2002. Transient dynamics in metapopulation response to perturbation. - Theor. Popul. Biol. 61: 285-295.

Pärtel, M. et al. 2011. Dark diversity: Shedding light on absent species. - Trends Ecol. Evol. 26: 124-128.

Pärtel, M. et al. 2013. Community Completeness: Linking Local and Dark Diversity within the Species Pool Concept. - Folia Geobot. 48: 307-317.

Pickett, S. T. A. 1989. Space-for-time substitution as alternative for long-term studies. - In: Likens, G. E. (ed), Long-term studies in Ecology. Springer New York, pp. 110-135.

R Development Core Team 2013. R Software.

Ronk, A. et al. 2015. Applying the dark diversity concept to plants at the European scale. Ecography 38: 1015-1025.

Rosenberg, K. V. et al. 2019. Decline of the North American avifauna. - Science 366: 120-124.

Sandel, B. 2019. Disequilibrium in trait-climate relationships of trees and birds. - Front. Ecol. Evol. 7: 138. doi: $10.3389 /$ fevo in press.

Sandel, B. et al. 2011. The Influence of Late Quaternary Climate-Change Velocity on Species Endemism. - Science 334: 660-664.

Sanderson, E. W. et al. 2002. The Human Footprint and the Last of the Wild. - Bioscience 52: 891.

Stephens, P. A. et al. 2016. Consistent response of bird populations to climate change on two continents. - Science 352: 84-87.

Tilman, D. et al. 1994. Habitat destruction and the extinction debt. - Nature 371: 65-66.

Walker, L. R. et al. 2010. The use of chronosequences in studies of ecological succession and soil development. - J. Ecol. 98: 725-736.

Wood, S. N. 2006. Generalized additive models: an introduction with R. - Chapman and Hall/CRC.

Zobel, M. et al. 2011. The formation of species pools: historical habitat abundance affects current local diversity. - Glob. Ecol. Biogeogr. 20: 251-259. 


\section{Supplementary materials}

Figure S1. Dark diversity threshold. Impact of the threshold used to calculate the community completeness index. The $5 \%$ threshold used in the study (x-axis) is compared to the $1 \%$ (blue, $y$-axis) and $10 \%$ (brown, $y$-axis) thresholds.

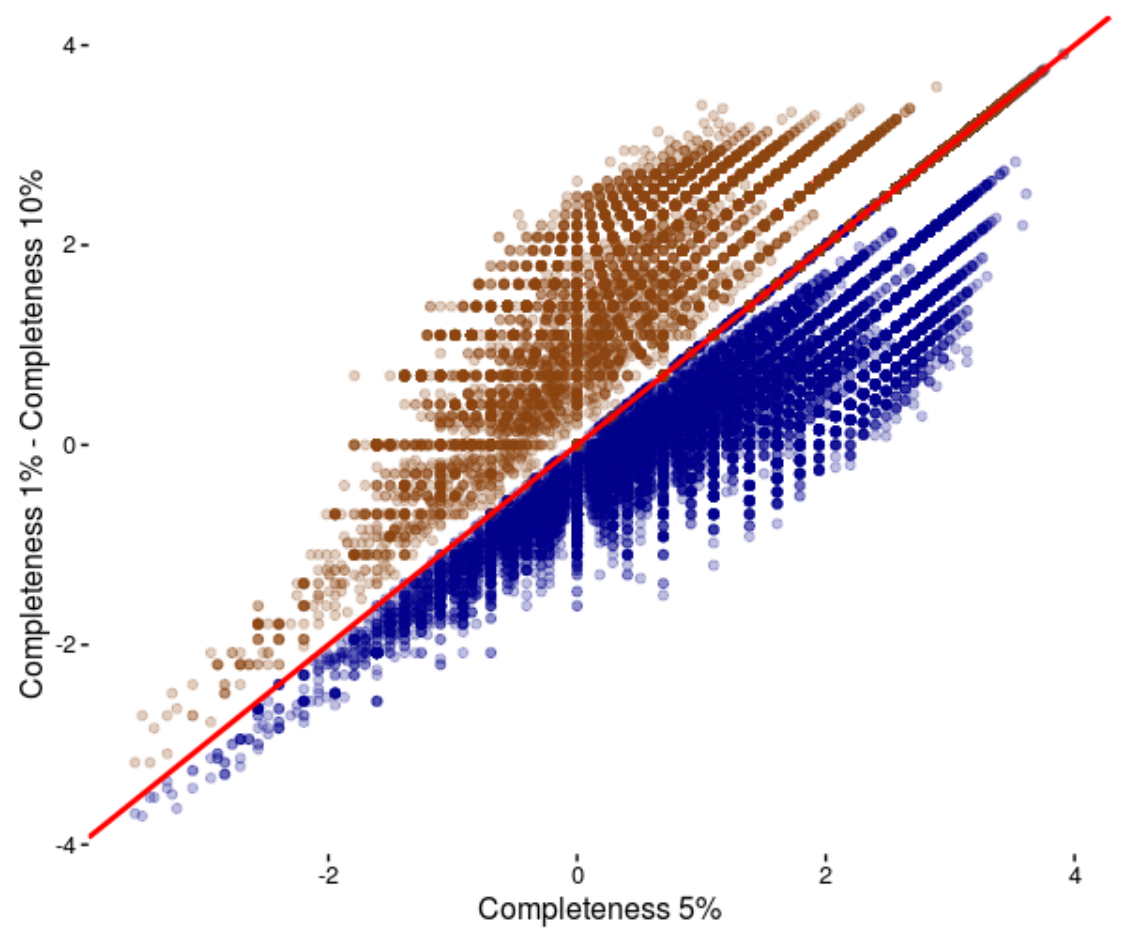


Figure S2. Collinearity between predictors. Pairwise correlations of the final set of predictors incorporated in our analysis : Human Impact Index (HII, line 1), \% of natural areas (Natural, line 2), colonization-extinction ratio (colExtRation, line 4), community completeness (completeness, line 5 ).

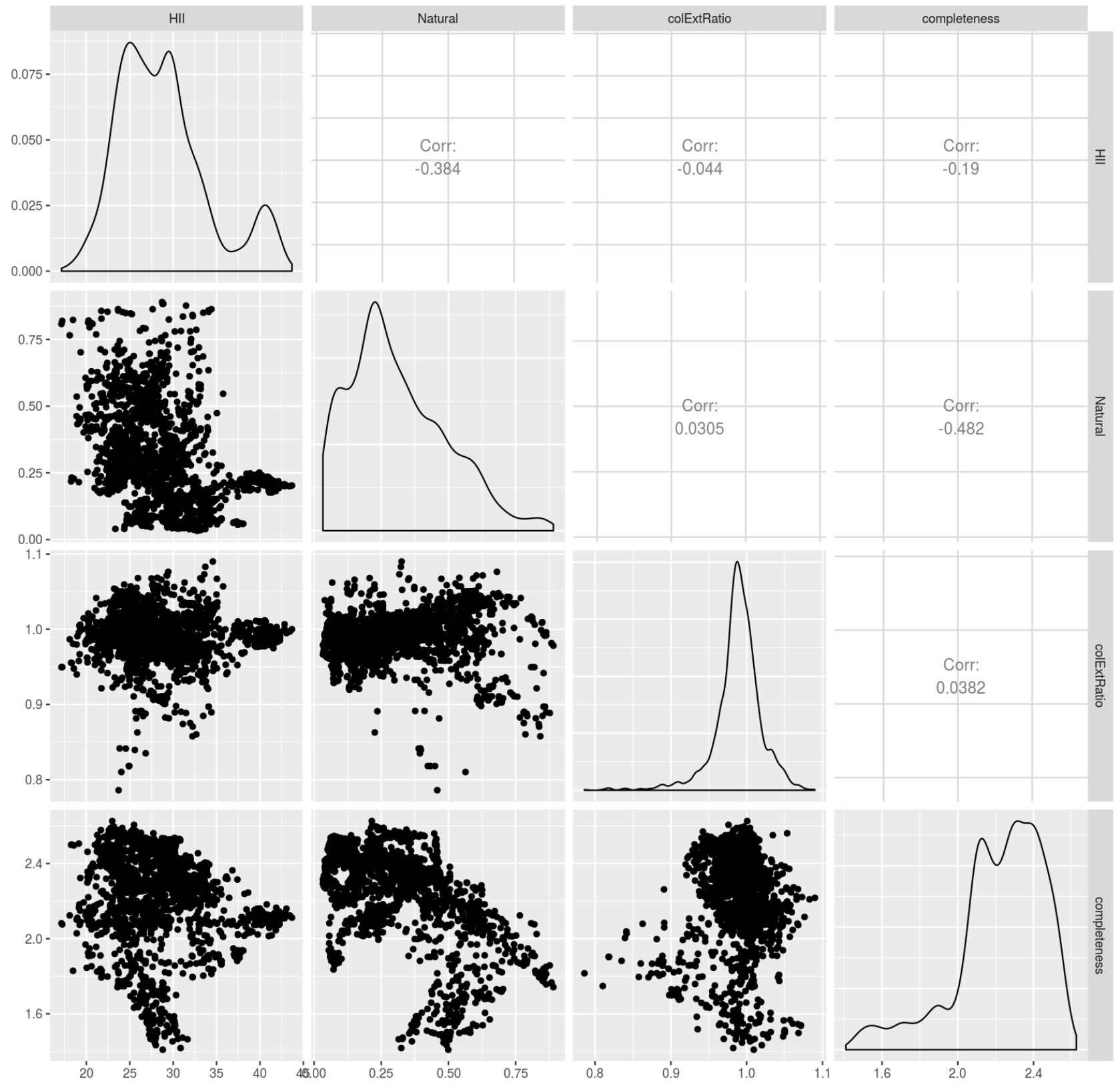


Figure S3. Species' examples. Scatterplots of relative temporal trends (y-axis) vs relative abundance showing space-time deviation (the lighter the color the more positive space-time deviation) for local species populations for (a) the European crested tit, Lophophanes cristatus; (b) the Eurasian collared dove Streptopelia decaocto; (c) the Common blackbird, Turdus Merula. The black line represents equality between relative population trend and relative population size where DV are equal to zero. The shaded, blue line represents the linear relationship (slope \pm SE) between temporal trends and relative abundance.
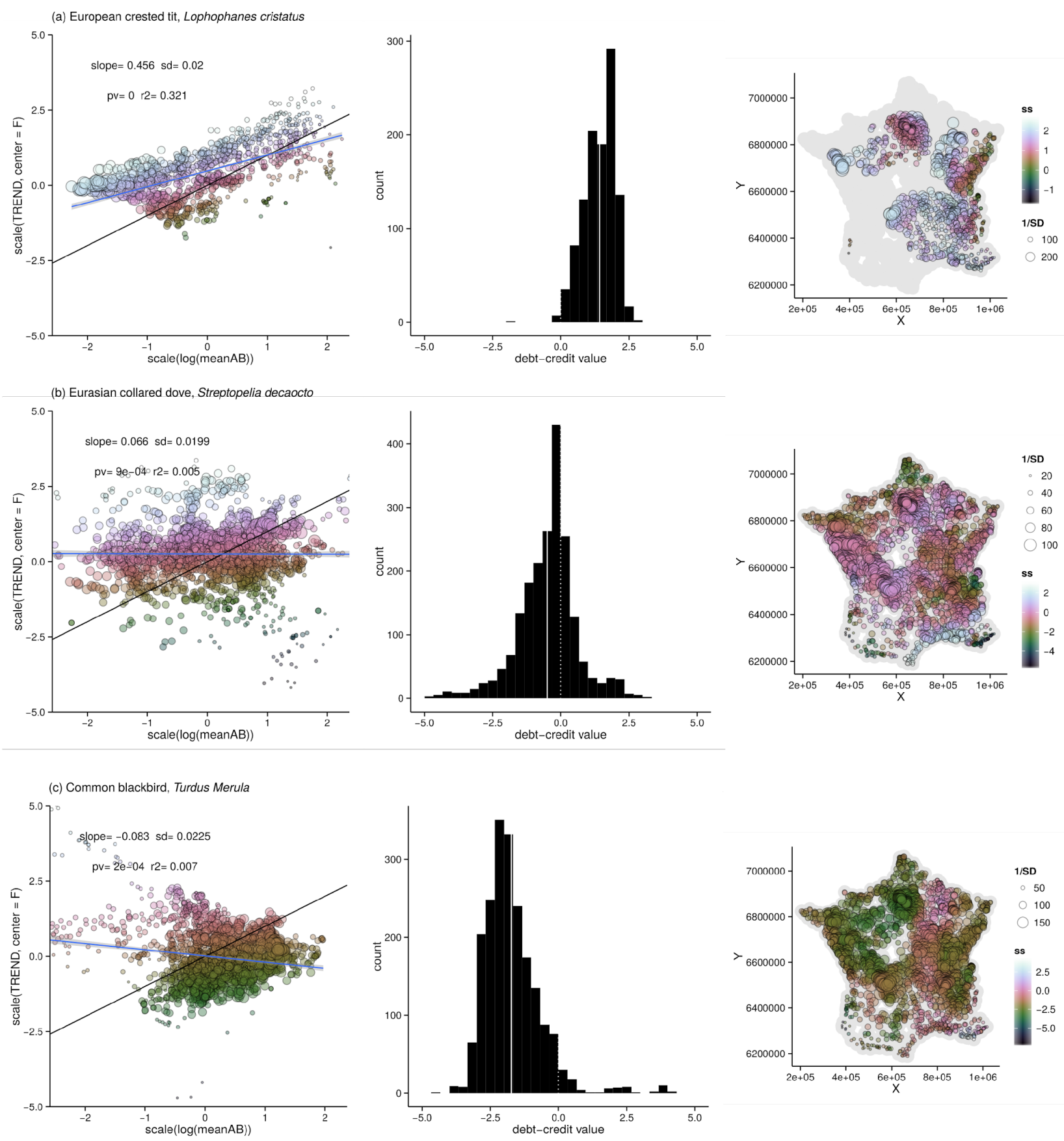
Figure S4. Scatterplots of space-time deviation (here called DV) estimated from bird abundance ( $x$-axis) vs (a) species richness ( $\left.D V_{\text {richness }}\right)$ or (b) biomass $\left(D V_{\text {mass }}\right)$ of local communities. The black line represents the 1:1 median. For a given site/year the biomass was calculated as $\sum_{i}\left(M_{i} \times n_{i}\right)$ where Mi and ni are respectively the bodymass and the abundance of the i-th species.
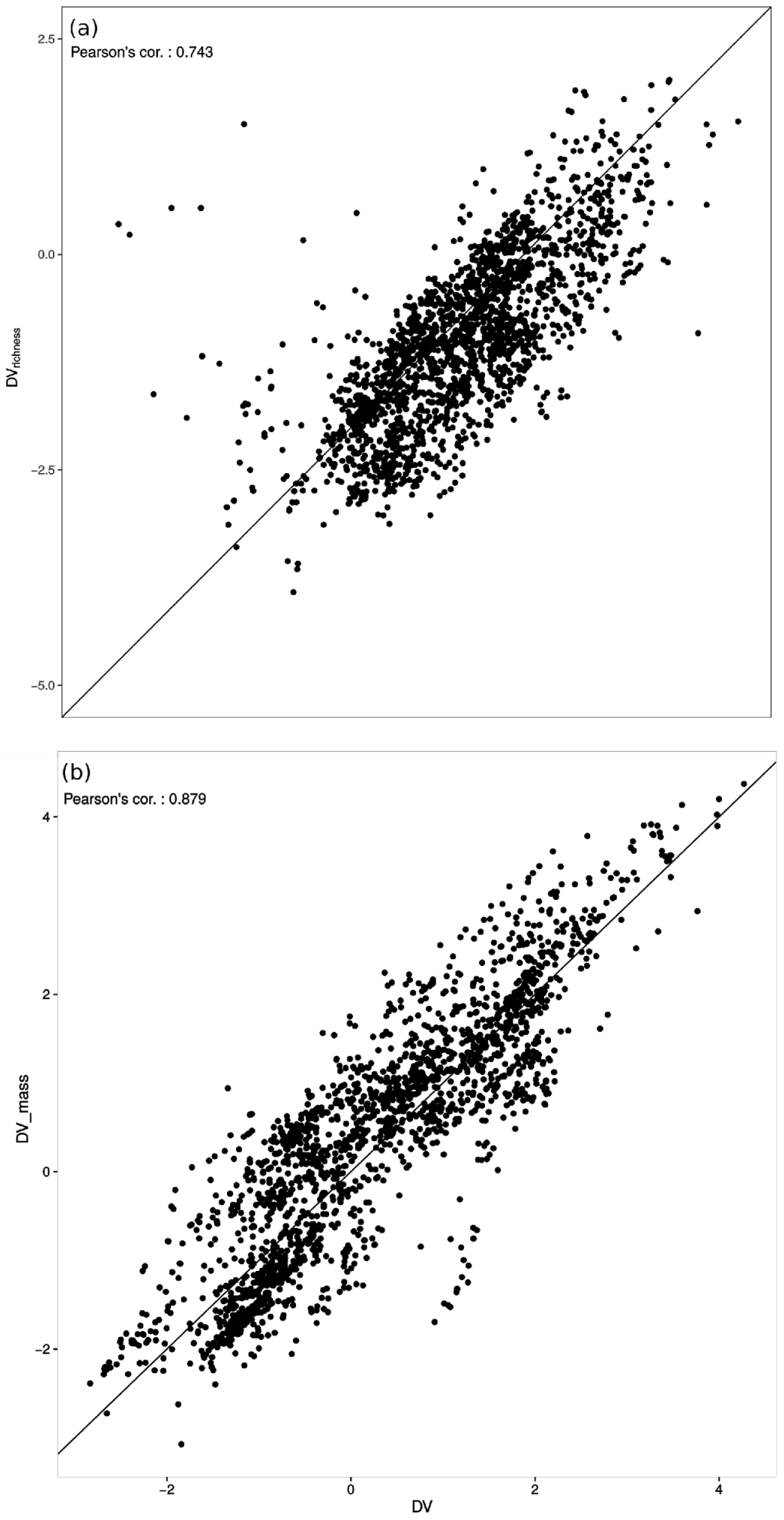
Figure S5. Underlying correlations between space-time deviation (here called DV, left panel), relative population growth rate (mid panel) and relative population size (right panel) and (a) community completeness, (b) \%of Natural areas and (c) Human influence index.

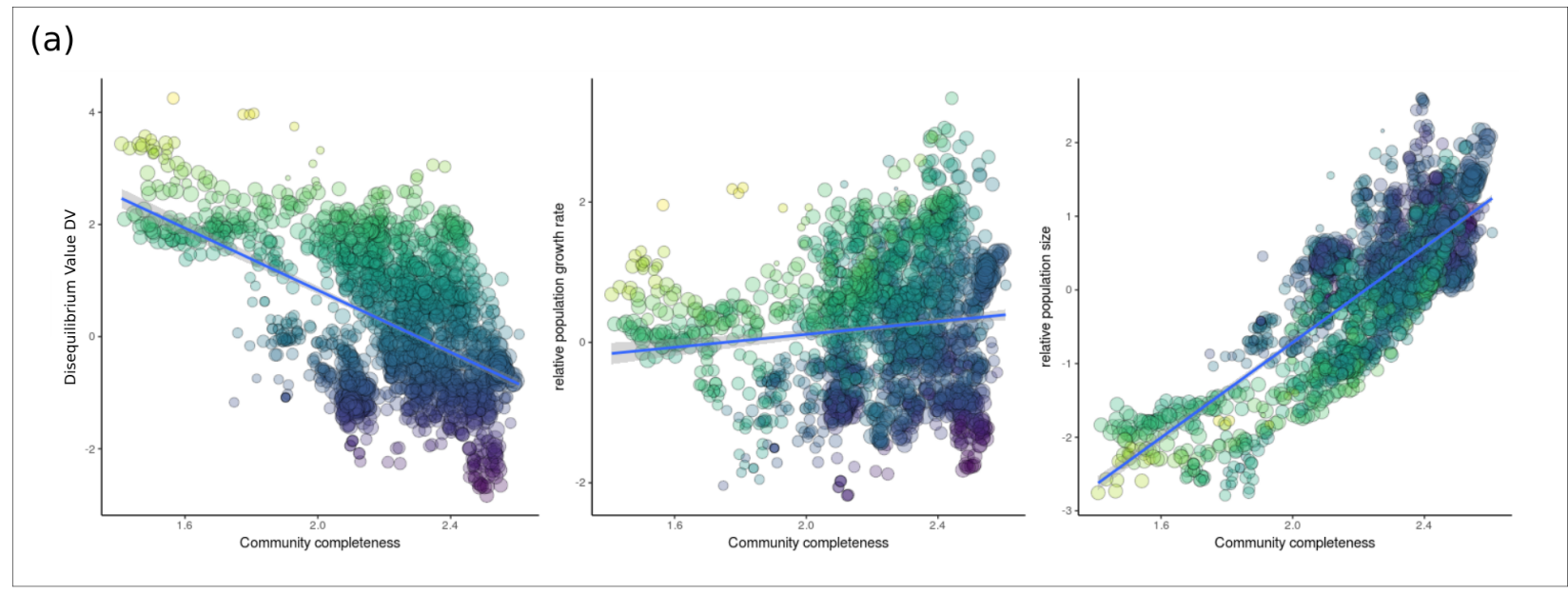

(b)
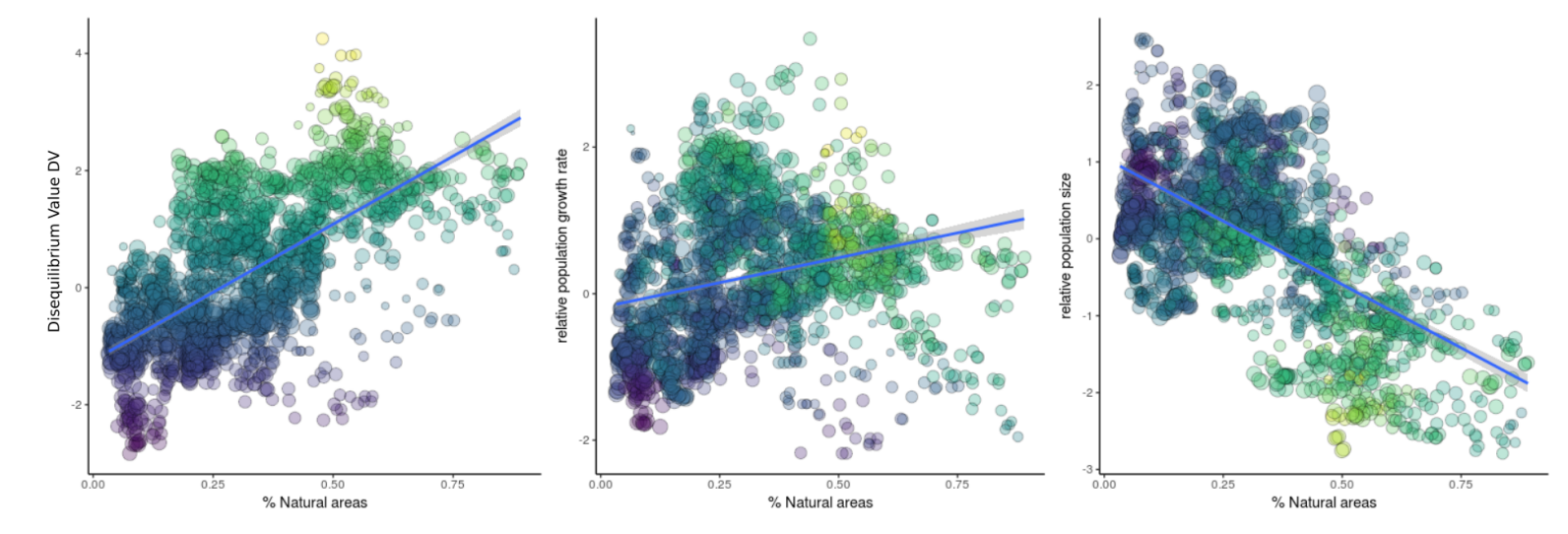

(c)
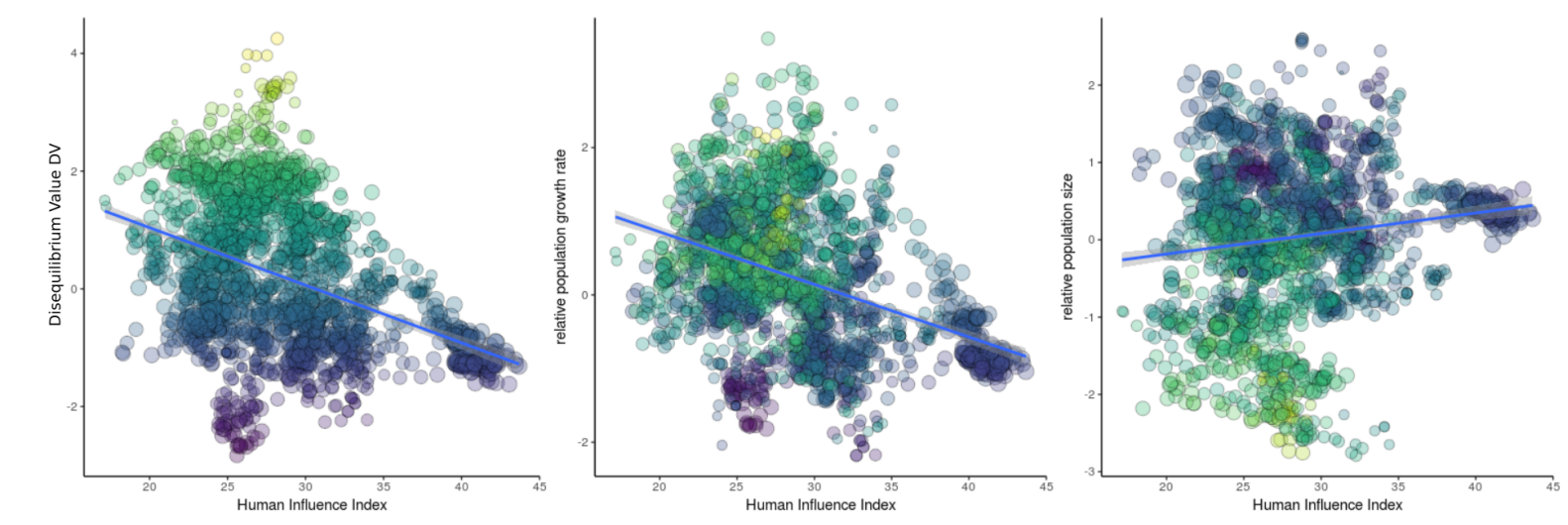